\title{
Soft models of competence assessment in professional education
}

\author{
Yuri Dashko ${ }^{1}$, Olga Vitchenko ${ }^{1, *}$, and Maxim Kadomtsev ${ }^{1}$ \\ Don State Technical University, Gagarin Square, 1, Rostov-on-Don, 344003, Russia
}

\begin{abstract}
The article presents the results of research on the problem of finding new models for assessing students ' competencies in the context of global trends in modern professional education - the merger of competence and project approaches, the development of e-learning, and the introduction of digital technologies to support expert systems. An original development of one of the soft models of fuzzy multiparametric assessment of competencies is proposed, and the mathematical apparatus of the model is described taking into account the requirements of fuzzy logic.
\end{abstract}

\section{Introduction. Development of a competency model}

The modern model of education, built on a competency-based approach, is the main one in educational systems around the world [1-3]. However, the problems associated with the development of a system of competencies, criteria and mechanisms for their assessment have not yet been fully resolved and are the subject of discussion. To date, there is no single universal system for assessing competencies [4-6].

At the same time, taking into account the need to introduce electronic learning management systems into the learning process, it is necessary to develop a competency model with indicators of competencies, which makes it possible to automate the assessment of the development of competencies by students [7-8].

Taking into account these conditions for the development of a competency model, it is necessary to take into account the existing uncertainty when assessing the development of competencies by students. This is a consequence of the fact that competence is not a set of fixed knowledge and skills and can be formed in several different ways, even within the framework of one learning process. As a consequence, most indicators of achievement of competencies cannot be directly measured values and are based on expert judgment.

Successful attempts to reduce uncertainty through statistical data processing were undertaken, for example, in [9]. However, a significant drawback of this approach can be called the attachment of research results to a specific training system.

Summing up, we can formulate the following requirements for the developed model for assessing the achievement of competencies [10-12]:

1. Indicators of achievement of competencies should cover all types of activities in the process of which the development of competencies occurs.

*Corresponding author: owinf@mail.ru 
2. The fact that a number of indicators of achievement of competencies cannot be directly measured and are probabilistic in nature should be taken into account.

3. The constructed system of competency indicators should be suitable for automation, including using the mathematical apparatus of neural networks.

For the implementation of the described requirements in the competence model, the apparatus of fuzzy logic is most suitable, and specifically, the mechanism of fuzzy multiparameter choice described in [13-15].

\section{Description of the mathematical apparatus of the procedure for fuzzy multi-parameter assessment of competencies}

We propose to consider the estimation process as multi-parameter optimization with fuzzy criteria. The optimization is based on the method of fuzzy multiparameter selection. Its mathematical description becomes possible after formalizing the optimization goal ("ideal" option) in the form of a vector of requirements, describing a variety of options and developing quality optimization criteria[16].

The generalized mathematical formulation of the choice problem can be represented by a set of the following form:

$$
<\mathrm{V}, \mathrm{F}, \mathrm{PT}, \mathrm{L}, \mathrm{W}, \mathrm{T}, \mathrm{A}>
$$

where the initial ones are:

$\mathrm{V}$ - many alternatives;

F - a set of descriptions of alternatives;

PT - set of outcomes of alternatives;

$\mathrm{L}$ - vector criterion for assessing the outcome;

$\mathrm{W}-$ is the preference structure.

It is necessary to construct some solution (rule) or algorithm $\mathrm{T}$ that allows performing the required action A over the set of alternatives $\mathrm{V}$.

The structure of preferences determines the procedure for comparing estimates $L(P)$, and the decision rule (or algorithm) $\mathrm{T}$ determines the principle of choosing elements from the set $\mathrm{V}$ based on the results of comparison in accordance with the required action $\mathrm{A}$.

Then the mathematical description of the selection procedure consists in disclosing the content of the above components (1), taking into account the characteristics of the initial data. The uniformity of the description of the system and its elements allows us to consider them in general terms as options for design solutions. Therefore, the superscript is omitted below.

Many alternatives consist of a finite number of elements:

$$
V=\left\{V_{I}, i=1\right\}
$$

each of which is described by a fuzzy vector of parameters:

$$
V_{i}: \bar{P}_{i}=\left[p_{\mathrm{i} 1}, \mathrm{p}_{\mathrm{i} 2}, \ldots, \mathrm{p}_{\mathrm{ij}}, \ldots, \mathrm{p}_{\mathrm{im}}\right]
$$

The ideal option is described by a vector of requirements:

$$
\bar{P}_{T}=\left[p_{T 1}, p_{T 2}, \ldots, p_{\mathrm{Tj}}, \ldots, \mathrm{p}_{\mathrm{Tm}}\right]
$$

The importance of the requirements parameter is taken into account when setting the preference vector: 


$$
\bar{W}=\left[w_{1}, \mathrm{w}_{2}, \ldots, \mathrm{w}_{j}, \ldots, \mathrm{w}_{m}\right] \quad 8,5 \mathrm{~nm}
$$

The given initial data establish the rank of the selection model:

$$
\operatorname{Rang}(T)=m \times n
$$

In general, it is convenient to present the initial data in the form of a matrix of a problem situation:

$$
\left\|P_{\text {ij }}\right\| ; \quad \mathrm{i}=\overline{1, \mathrm{n},} \quad \mathrm{j}=\overline{1, \mathrm{~m}}
$$

where $P_{i j}$ is the assessment of the $\mathrm{i}$-th option by the $\mathrm{j}$-parameter;

$\mathrm{n}$ is the number of parameters used;

$\mathrm{m}$ is the number of solutions.

This form of presentation allows you to visually reflect the initial information (see Table 1).

Table 1. Tabular form of source information

\begin{tabular}{|c|c|c|c|c|c|c|}
\hline Parameters Options & $\mathbf{P}_{\mathbf{1}}$ & $\mathbf{P}_{\mathbf{2}}$ & $\cdots$ & $\mathbf{P}_{\mathbf{i}}$ & $\cdots$ & $\mathbf{P}_{\mathbf{m}}$ \\
\hline $\mathrm{V}_{1}$ & & & & & & \\
\hline $\mathrm{V}_{2}$ & $\mathrm{P}_{11}$ & $\mathrm{P}_{12}$ & $\ldots$ & $\mathrm{P}_{1 \mathrm{j}}$ & $\ldots$ & $\mathrm{P}_{1 \mathrm{~m}}$ \\
\hline$\ldots$ & $\mathrm{P}_{12}$ & $\mathrm{P}_{22}$ & $\ldots$ & $\mathrm{P}_{2 \mathrm{j}}$ & $\ldots$ & $\mathrm{P}_{2 \mathrm{~m}}$ \\
\hline $\mathrm{V}_{\mathrm{n}}$ & $\ldots$ & $\ldots$ & $\ldots$ & $\ldots$ & $\ldots$ & $\ldots$ \\
\hline
\end{tabular}

The decision-making procedure can be represented as a sequence of actions for assessing, ranking and selecting options in accordance with a system of criteria.

The set-theoretic approach used in this work is based on a step-by-step narrowing of the set of possible design solutions. The selection stages can be viewed as a kind of filters that filter out unsatisfactory options. The filtering process is the process of making a decision on the choice of options.

Typical links in the decision-making chain are the assessment of possible options, their ranking and subsequent selection of the most preferable ones among them. The decision making process is shown schematically in Figure 2 from which it can be seen that at the first stage, the initial finite set of introduced constraints $\mathrm{F}$ is narrowed. As a result, a set of admissible options is formed $\mathrm{V}_{\mathrm{d}}=\mathrm{V} \cap \mathrm{F}$.

Then, after evaluating the options in accordance with the selected criteria, the set $V_{d}$ narrows down to a set of rational options. The set $\mathrm{V}_{\mathrm{r}}$ contains the desired solution obtained by introducing additional preferences or by directly specifying the variant.

Thus, the task of choosing options under conditions of uncertainty in the initial data for a specific application essentially consists in choosing a system of preference criteria.

An important point in the decision-making process for choosing an option is the choice of evaluation criteria - the evaluation function L. This choice largely determines the nature of the process. Taking into account the peculiarities of the apparatus of fuzzy sets and the fact that in this case it is important for us the mutual arrangement of the options on a common scale, and not the grouping of these options, the mismatch measure based on the weighted Hamming distance was used in the work:

$$
L_{i}=\bar{W} \times\left(\bar{\Pi}_{T}-\bar{\Pi}_{i}\right)
$$

It is obvious that the inclusion of qualitative, imprecise estimates will lead to the appearance of an uncertain total estimate of $\mathrm{L}$ and, accordingly, a certain share of the risk 
of making a non-optimal decision. But this uncertainty along with the uncertainty of quantitative parameters must be taken into account in the selection process. If there is uncertainty in the initial data, the indicator (8) cannot be used explicitly, since it does not provide for working with fuzzy values.

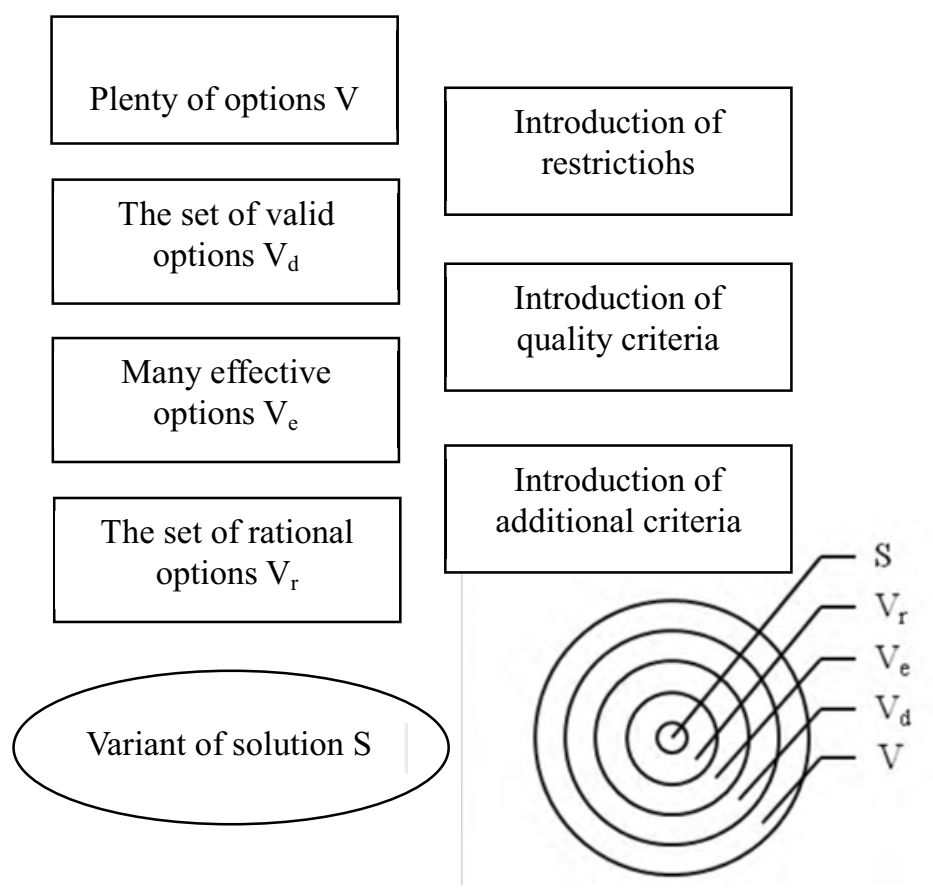

Fig. 2. A method of fuzzy multi-parameter selection

\section{Description of the system of competency indicators and their assessment in accordance with the method of fuzzy multi- parameter choice}

Indicators of achievement of competencies by students are the main structural elements of a competence that reveal its essence.

Indicators of achievement of competencies by students can be:

- presented as generalized characteristics, clarifying and revealing the formulation of competence in the form of specific actions performed by a graduate who has mastered this competence;

- presented as learning outcomes;

- comparable to labor functions and (or) labor actions (professional standard), but not identical to them;

- comparable with the complex of KS (Knowledge-Skills), but not identical to them (see Figure 3). 

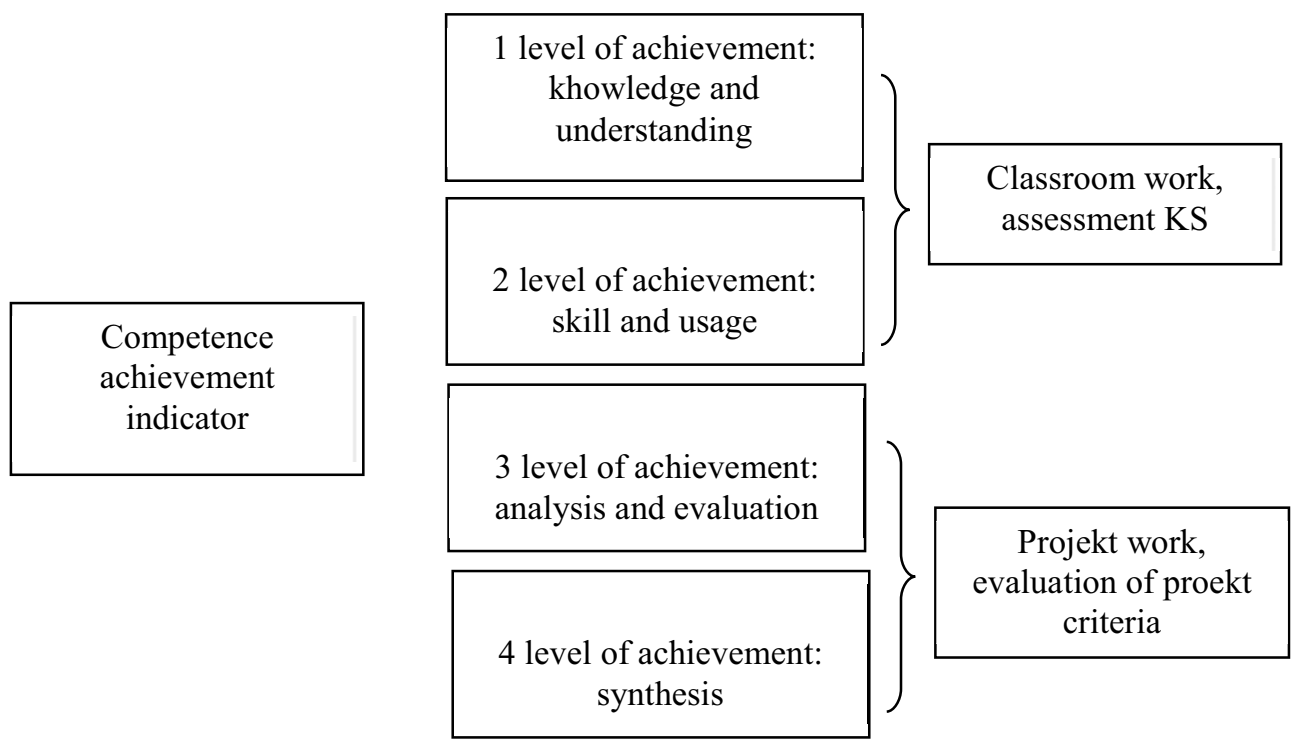

Fig. 3. Levels of achievement of competence indicators

Project is a discipline section in which indicators of competencies of 3 and 4 levels are formed. KS are a discipline section in which indicators of competencies of 1 and 2 levels are formed (knowledge and skills necessary for the implementation of the project).

Project criteria - decision-making rules for assessing the formation of competence.

KS criteria - decision-making rules for assessing the ownership of KS.

Varieties of disciplines.

1. The discipline itself is a discipline in which only knowledges and skills are formed (1 and 2 levels of achievement of competencies).

2. Project is a discipline in which competencies of 3 and 4 levels are formed (knowledge and skills are formed in disciplines of type 1).

3. Discipline-project - a discipline in which competencies are formed at all 4 levels.

A module is a set of individual educational elements that have a certain logical completeness in relation to the goals and learning outcomes.

1. Module - discipline.

2. A discipline module is a part of a discipline (a set of discipline content sections).

3. Curriculum module - a set of disciplines.

4. Module of the educational process - the time period for which the disciplines or their parts are studied.

5. Project module - a part of the project in which a certain indicator of competence is achieved.

6. Discipline module - a part of the discipline in which the KS are formed, which are necessary for the successful implementation of the project module.

The competency model assessment system is shown in figure 4. 
Discipline assessment

(1 type of discipline)

\begin{tabular}{|c|}
\hline KS rating \\
\hline $\begin{array}{c}\text { Performance } \\
\text { evaluation } \\
\text { criteria of the } \\
\text { proekt }\end{array}$ \\
\hline
\end{tabular}
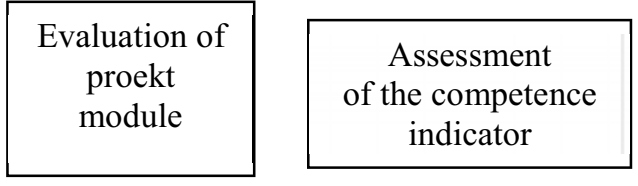

Assessment

of competence

\section{Proekt evaluation \\ (2 type of discipline)}

Discipline assessment

(3 type of discipline)

Fig. 4. The process of evaluation of competencies

Further, table 1 presents formulas for evaluating elements in the structural model of competencies, table 2-weight coefficients for calculations.

Table 1. Formulas for evaluating elements in the structural model of competencies

\begin{tabular}{|l|c|c|}
\hline \multicolumn{1}{|c|}{ Name of the structural element } & $\begin{array}{c}\text { Designation of a } \\
\text { structural element }\end{array}$ & $\begin{array}{c}\text { Designation of } \\
\text { the structural } \\
\text { element rating }\end{array}$ \\
\hline Competence & $\mathrm{GC}$ & $\mathrm{RGC}$ \\
\hline Competence block & $\mathrm{BC}_{\mathrm{i}}$ & $\mathrm{RBC}_{\mathrm{i}}$ \\
\hline Competence & $\mathrm{C}_{\mathrm{ij}}$ & $\mathrm{RC}_{\mathrm{ij}}$ \\
\hline The indicator of competence & $\mathrm{IC}_{\mathrm{ijk}}$ & $\mathrm{RIC}_{\mathrm{ijk}}$ \\
\hline Project module for the competence indicator & $\mathrm{MP}_{\mathrm{ijk}}$ & $\mathrm{RMP}_{\mathrm{ijk}}$ \\
\hline KS for the project module & $\mathrm{MS}_{\mathrm{ijk}}$ & $\mathrm{RMS}_{\mathrm{ijk}}$ \\
\hline Criteria for the competence indicator in the project & $\mathrm{PIC}_{\mathrm{ijk}}$ & $\mathrm{RPIC}_{\mathrm{ijkl}}$ \\
\hline $\begin{array}{l}\text { KS for the criterion of the indicator competencies } \\
\text { (module KS) }\end{array}$ & $\mathrm{PICS}_{\mathrm{ijkl}}$ & $\mathrm{RPICS}_{\mathrm{ijkl}}$ \\
\hline $\begin{array}{l}\text { Individual elements of KS (lectures, practices, } \\
\text { laboratory) }\end{array}$ & $\mathrm{Sijklp}_{\mathrm{j}}$ & $\mathrm{RSijklp}$ \\
\hline Discipline (type 1) & $\mathrm{D}_{\mathrm{i}}$ & $\mathrm{RD}_{\mathrm{i}}$ \\
\hline Discipline module & $\mathrm{MD}_{\mathrm{ij}}$ & $\mathrm{RMD}_{\mathrm{ij}}$ \\
\hline Project (type 2) & $\mathrm{P}_{\mathrm{i}}$ & $\mathrm{RP}_{\mathrm{i}}$ \\
\hline The project module & $\mathrm{MP}_{\mathrm{ij}}$ & $\mathrm{RMP}_{\mathrm{ij}}$ \\
\hline Discipline-project (type 3) & $\mathrm{DP}_{\mathrm{i}}$ & $\mathrm{RDP}_{\mathrm{i}}$ \\
\hline Discipline-project module & $\mathrm{MDP}_{\mathrm{ij}}$ & $\mathrm{RDP}_{\mathrm{ij}}$ \\
\hline
\end{tabular}

Table 2. Weight coefficients for calculations

\begin{tabular}{|l|c|}
\hline \multicolumn{1}{|c|}{ The names of the weight coefficients } & $\begin{array}{c}\text { The designation of the } \\
\text { weighting factors }\end{array}$ \\
\hline $\begin{array}{l}\text { KS assessment for the competence indicator criterion (KS } \\
\text { module) }\end{array}$ & $\alpha_{\mathrm{ij}} \mathrm{klp}$ \\
\hline $\begin{array}{l}\text { Assessment of KS for the competence indicator (project } \\
\text { module) }\end{array}$ & $\beta_{\mathrm{ij}} \mathrm{kl}$ \\
\hline Evaluation of criteria for the competence indicator in the project & $\gamma_{\mathrm{ij}} \mathrm{kl}$ \\
\hline Assessment of the competence indicator & $\delta_{\mathrm{ij}} \mathrm{k}$ \\
\hline Assessment of competence & $\varepsilon_{\mathrm{ij}} \mathrm{k}$ \\
\hline Assessment of the competence block & $\mu_{\mathrm{ij}}$ \\
\hline The evaluation of competences (competence) & $v_{\mathrm{i}}$ \\
\hline Discipline assessment & $\rho_{\mathrm{ijk}}$ \\
\hline
\end{tabular}


KS assessment for the competence indicator criterion (KS module)

$$
\operatorname{RPICS}_{i j k l}=\sum_{p=1}^{3} \alpha_{i j k l p} R S_{i j k l p}, \sum_{p=1}^{3} \alpha_{i j k l p}=1
$$

Assessment of KS for the competence indicator (project module)

$$
R M S_{i j k}=\sum_{l} \beta_{i j k l} \operatorname{RPICS}_{i j k l}, \sum_{l} \beta_{i j k l}=1
$$

Evaluation of criteria for the competence indicator in the project

$$
R M P_{i j k}=\sum_{l} \gamma_{i j k l} R P I C_{i j k l}, \sum_{l} \gamma_{i j k l}=1
$$

Assessment of the competence indicator

$$
R I C_{i j k}=\delta_{i j k} R M P_{i j k}+\varepsilon_{i j k} R M S_{i j k}, \quad \sum\left(\delta_{i j k}+\varepsilon_{i j k}\right)=1
$$

Assessment of competence

$$
R C_{i j}=\sum_{k} \lambda_{i j k} R I C_{i j k}, \sum_{k} \lambda_{i j k}=1
$$

The evaluation of competences (competence)

$$
R G C=\sum_{i} v_{i} R B C_{i}, \sum_{i} v_{i}=1
$$

The discipline, in general, contains a set of project modules and their corresponding KS modules. The assessment of each set (project module $-\mathrm{KS}$ module) coincides with the assessment of the competency indicator. The sets of the project module - the KS module (competency indicators) in competencies and in disciplines differ from each other, therefore it is necessary to match the modules of the disciplines and the corresponding competency indicators $\mathrm{MDP}_{\mathrm{ij}}$ and $\mathrm{IC}_{\mathrm{ijk}}$. Then, to assess the discipline (type 3), we have a formula similar to (13):

$$
R D P_{i}=\sum_{j} \rho_{i j k} R M D P_{i j}, \sum_{k} \rho_{i j k}=1
$$

$\mathrm{RMDP}_{\mathrm{ij}}$ are calculated by formulas similar to (12). For disciplines of type 1, the coefficients are $\delta_{\mathrm{ijk}}=0$ for disciplines of type $2 \varepsilon_{\mathrm{ijk}}=0$.

Thus, we have presented one of the possible approaches to designing a soft model for assessing competencies in the vocational education system, taking into account the uncertainty of indicators of their achievement by students.

\section{References}

1. C. Qiu, X. Feng, J. D. Reinhardt, J. Li, Development and psychometric testing of the Research Competency Scale for Nursing Students: An instrument design study, Nurse Education Today, 79, 198-203 (2019)

2. P. Guo, N. Saab, L. S. Post, W. Admiraal, A review of project-based learning in higher education: Student outcomes and measures, International Journal of Educational Research, 102, (2020) doi:/10.1016/j.ijer.2020.101586

3. J. Enke, K. Kraft, J. Metternich, Competency-oriented Design of Learning Modules, Procedia CIRP, 32, 7-12 (2015)

4. R. Atiq, A. O. K. Rahmat, M. Yazmil Md. Yatim, K. N. A. Maulud, N. I. Md. Yusoff, A. A. Mutalib, The Effectiveness of basic Design Project (Cornerstone) in Students' 
Competency Development, Procedia - Social and Behavioral Sciences, 60, 56-60 (2012)

5. R. Glass, J. Metternich, Method to measure competencies - a concept for development, design and validation, Procedia Manufacturing, 45, 37-42 (2020)

6. H. Thebuwana, R. Hadgraft, F. Alam, Addressing Graduate Competencies: Understanding the Contextual Factors Impacting the Engineering Discipline, Energy Procedia, 110, 359-364 (2017) doi:10.1016/j.egypro.2017.03.153

7. I. M. Arievitch, The vision of Developmental Teaching and Learning and Bloom's Taxonomy of educational objectives, Learning, Culture and Social Interaction, 25, (2020) doi:10.1016/j.lcsi.2019.01.007

8. G. K. Nithyanandam, A framework to improve the quality of teaching-learning process - A case study,Procedia Computer Science, 172, 92-97 (2020) doi:10.1016/j.procs.2020.05.013

9. M. Farashahi, M. Tajeddin, Effectiveness of teaching methods in business education: A comparison study on the learning outcomes of lectures, case studies and simulations, The International Journal of Management Education, 16(1), 131-142 (2018) doi:10.1016/j.ijme.2018.01.003.

10. S. J. Brame, Writing Learning Objectives Using Bloom's Taxonomy,Science Teaching Essentials, Academic Press, 16(1), 29-34 (2019)doi:10.1016/B978-0-12-814702$3.00025-1$

11. Y. Zhu, H. Lu, P. Qiu, K. Shi, J. Chambua, Z. Niu, Heterogeneous teaching evaluation network based offline course recommendation with graph learning and tensor factorization, Neurocomputing, 415, 84-95, (2020) doi:10.1016/j.neucom.2020.07.064.

12. M. Goodsett, Best practices for teaching and assessing critical thinking in information literacy online learning objects, The Journal of Academic Librarianship, 46(5), 102106 (2020) doi:10.1016/j.acalib.2020.102163

13. M. N. Mokhtarian, A note on "Developing global manager's competencies using the fuzzy DEMATEL method", Expert Systems with Applications, 8, 9050-9051 (2011) doi:10.1016/j.eswa.2011.01.080

14. J. S. Jeong, D. González-Gómez, Assessment of sustainability science education criteria in online-learning through fuzzy-operational and multi-decision analysis and professional survey, Heliyon, 6 (2020) doi:10.1016/j.heliyon.2020.e04706

15. M. A. S. Machado, T. D. R. G. Moreira, L. F. A. M. Gomes, A. M. Caldeira, D. J. Santos, A Fuzzy Logic Application in Virtual Education, Procedia Computer Science, 91, 19-26 (2016) doi:10.1016/j.procs.2016.07.037

16. O. Vitchenko, Y. U. Dashko, E. Tishchenko, L. Sakharova, Method of identification of extremist texts in the russian language based on the fuzzy logic, advances in intelligent systems and computing, 1095, 259-265 (2020) 